\title{
MEMBERDAYAKAN DAN MEMBANGUN MASYARAKAT PURASEDA MELALUI PENDIDIKAN SERTA BERAKHLAKUL KARIMAH
}

\author{
Ade Hendri Hendrawan ${ }^{1}$, Wulan Desi Maulani, Siti Indriyani ${ }^{2}$ \\ hendri@uika-bogor.ac.id \\ Dosen Fakultas Teknik ${ }^{1}$, Mahasiswa KKN Kelompok 61 Tahun $2018^{2}$
}

\begin{abstract}
ABSTRAK
Penelitian ini bertujuan untuk memberdayakan dan membangun masyarakat puraseda melalui pendidikan serta berakhlakul karimah, dengan menggunakan penerapan metode Participatory Rural Appraisal(PRA) Penelitian ini merupakan Penelitian Deskriptif pencarian fakta dengan interpretasi yang tepat. Penelitian deskriptif mempelajarai masalah-masalah dalam masyarakat serta tata cara yang berlaku dalam masyarakat serta situasi-situasi tertentu, termasuk tentang hubungan, kegiatan-kegiatan, sikap-sikap, pandangan-pandangan, serta proses-proses yang sedang berlangsung dan pengaruh-pengaruh dari suatu fenomena. Dalam metode deskriptif, peneliti bisa saja membandingkan fenomena-fenomena tertentu sehingga merupakan suatu studi komparatif. Adakalanya peneliti mengadakan klasifikasi, serta penelitian terhadap fenomena-fenomena dengan menetapkan suatu standar atau suatu norma tertentu sehingga banyak ahli menamakan metode deskriptif ini dengan nama survei normatif (normative survey). Dengan metode deskriptif ini juga diselidiki kedudukan (status) fenomena atau faktor dan melihat hubungan antara satu faktor dengan faktor yang lain. Karenanya metode deskriptif juga dinamakan studi status (satus study). Hasil dari penelitian tersebut dalam bidang Pendidikan di Kp.Cigoong Rt 01-02 Rw 07 tergolong belum cukup baik dalam hal perhatian terhadap pentingnya pendidikan khususnya pendidikan untuk anak usia dini. Hal tersebut terlihat dari kurangnya kesadaran orangtua yang harus memiliki semangat tinggi menyekolahkan anaknya. Pemberian bimbingan belajar atau jam tambahan belajar untuk siswa SD dan SMP merupakan salah satu hal penting yang harus di perhatikan karena kemampuan anak dengan tingkat pendidikan yang ditempuh sesuai dengan yang diharapkan.
\end{abstract}

Kata Kunci : Membangun, Masyrakat, Pendidikan

\section{PENDAHULUAN}

\section{Latar Belakang}

Konsep Pemberdayaan pada perkembangan memiliki banyak definisi yang dikemukakan oleh para ahli yang memiliki komitmen tinggi terhadap usaha memajukan kesejahteraan masyarakat, seperti yang dikemukakan oleh Ife (1995 182), yaitu pemberdayaan berarti menyiapkan kepada masyarakat berupa sumberdaya, kesempatan, pengetahuan, dan keahlian untuk meningkatkan kapasitas diri masyarakat di dalam menentukan masa depan mereka, serta untuk berpartisipasi dan mempengaruh kehidupan dalam Komunitas masyarakat itu sendiri.

$\begin{array}{ccc}\text { Terkait } & \text { dengan } & \text { tujuan } \\ \text { pemberdayaan, } & \text { Sulistiyani } & \text { (2004) }\end{array}$


menjelaskan bahwa tujuan yang ingin dicapai daripemberdayaan masyarakat adalah untuk membentuk individu dan masyarakat menjadi mandiri. Kemandirian tersebut meliputi kemandirian berpikir, bertindak dan mengendalikan apa yang mereka lakukan.

Perlunya upaya pemberdayaan adalah berangkat dari kenyataan masih lemahnya posisi sebagian besar masyarakat dalam menuntut hak dan menjalankan kewajibannya ditunjukkan dengan kurang aksesnya mereka terhadap beberapa fasilitas, misalnya informasi, teknologi, permodalan usaha, hukum, dan kesehatan Berbagai kelemahan akses tersebut diawali dengan rendahnya tingkat pendidikan yang dimiliki oleh masyarakat kita terutama di pedesaaan yang ada di Kp Cigoong Rt 01/07, Desa Puraseda, Kec Leuwiliang. Kab. Bogor.

Pelaksanaannya dalam masyarakat ataupun sekolah di wujudkan dengan pelatihan/skill, mengajar dan tak lupa pentingnnya menanamkan akhlaqul karimah merupakan pondasi terpenting dalam segala aspek kehidupan. Seperti yang dikatakan Al-Ghazali "Ketika manusia mempunyai ilmu namun sulit untuk memahami jangan-jangan ada yang keliru, karena ilmu itu merupakan Nur atau Cahaya jadi kemungkinan ada yang menghalangi masuknya Nur ke dalam otak dan jiwa kita. Pentingnya memelihara akhlaq/adab agar senantiasanya terarah dan dalam keridhoan-Nya.

\section{Kondisi Wilayah}

Letak Geografis Desa Puraseda luas wilayahnya 390,440 $\mathrm{Ha}$, terdiri dari 12 RW,32 RT dan 4 Dusun. Yaitu Dusun 1-2 dan Dusun 3-4, dengan batas-batas wilayah sebagai berikut:

\begin{tabular}{|l|l|}
\hline Batas & Desa \\
\hline Sebelah Utara & Karyasari \\
\hline Sebelah Selatan & $\begin{array}{l}\text { Bantar Karet, Kec. } \\
\text { Nanggung }\end{array}$ \\
\hline Sebelah Timur & Purasari \\
\hline Sebelah Barat & Pabangbon \\
\hline
\end{tabular}

Jarak dari Desa Puraseda ke ibu kota Kecamatan Leuwiliang11 Km, jarak ke ibu kota Kabupaten Bogor 40 Km, jarak ke ibu kota Provinsi di Bandung $120 \mathrm{Km}$ dan jarak ke ibu kota Negara di Jakarta $60 \mathrm{Km}$.

Topografi Desa Puraseda merupakan desa yang berada didaerah dataran rendah, dengan ketinggian 600-700 meter diatas permukaan laut (mdpl). Sebagian besar wilayah desa adalah lahan pesawahan dan pemukiman dan kemiringanperbukitan antara $20^{\circ}-45^{\circ}$. Suhu rata-rata harian mencapai $30-42^{\circ} \mathrm{C}$.

Hidrologi Dan Klimatologi, Sumber air yang ada di Desa Puraseda meliputi air permukaan dan air tanah. Air permukaan berupa sungai. Sesuai dengan kebijakan penyediaan air baku untuk irigasi, maka di Desa Puraseda mendapat pasokan pelayanan irigasi berasal dari susukan Leuwijawa Sedangkan untuk kebutuhan rumah tangga, masyarakat sebagian menggunaan air bersih dari mata airdi antaranya:

1. Mata Air Terjun Cipuraseda

2. Mata Air Cikoneng/Muara Tilu

3. Mata Air Gunung Peuteuy

4. Mata Air Cipanas

Luas dan sebaran penggunaan lahan pada umumnya lahan yang berada atau terdapat di Desa Puraseda digunakan secara produktif, karena merupakan lahan yang subur terutama untuk lahan pertanian, jadi hanya sebagian kecil saja yang tidak dimanfaatkan oleh warga, hal ini pula menunjukan bahwa kawasan Desa 
Puraseda adalah daerah yang memiliki sumber daya alam yang memadai.

\section{METODE PENGABDIAN}

partisipasi masyarakat sudah lebih dari satu dasawarsa menjadi kata kunci dalam bahasa masyarakat pembangunan. Namun dalam kenyataannya program pembangunan dan pengembangan msyarakat masih juga dilakukan dengan cara lama yang mengabaikan konsep partisipasi. Program pembangunan masih saja diturunkan dari atas dan masyarakat tinggal melaksanakannya tanpa adanya keterlibatan langsung masyarakat yang menjadi sasaran program tersebut. Kalaupun ada penjajagan terhadap kebutuhan pembangunan, itupun dilakukan dengan cara survai, studi atau penelitian formal yang dilakukan oleh lembaga penelitian atau perguruan tinggi yang karena beberapa asumsi yang kurang tepat, maka program tidak menyentuh kebutuhan yang sesungguhnya. Dengan sendirinya dukungan masyarakat terhadap program tersebut menjadi pura-pura, demikian pula partisipasinya. yang berpengaruh terhadap keberlanjutan dari program tersebut.

Alasan-alasan yang demikian melahirkan beragam pemikiran tentang pendekatan pengembangan program yang lebih partisipatif. Istilah-istilah partisipasi masyarakat, perencanaan dari bawah (bottom-up planning), penyadaran, pendekatan yang berpusat pada petani (farmer centered approach), dll menjadi kosa kata para aktivis pembangunan, baik pemerintah maupun swasta, walaupun kenyataannya belum mencerminkan arti kata tersebut. Program-program yang ada masih saja tetap diturunkan dari atas (topdown approach ), direncanakan dari meja kantor, sementara masyarakat diperkenankan berpartisipasi dalam pelaksanaan fisik di lapangan, sehingga tingkatan partisipasinya masih layak disebut sebagai mobilisasi.

Demikian mendorong untuk diperkenalkannya salah satu metode dan teknik yang dikenal dengan Participatory Rural Appraisal(PRA), karena dipandang telah memiliki teknik-teknik yang dijabarkan cukup operasional dengan konsep bahwa keterlibatan masyarakat sangat diperlukan dalam seluruh kegiatan. Pendekatan PRA memang bercita-cita menjadikan masyarakat menjadi peneliti, perencana, dan pelaksana pembangunan dan bukan sekedar obyek pembangunan. Tekanan aspek penelitian bukan pada validitas data yang diperoleh, namun pada nilai praktis untuk pengembangan program itu sendiri. Penerapan pendekatan dan teknik PRA dapat memberi peluang yang lebih besar dan lebih terarah untuk melibatkan masyarakat. Selain itu melalui pendekatan PRA akan dapat dicapai kesesuaian dan ketepatangunaan program dengan kebutuhan masyarakat sehingga keberlanjutan (sustainability ) program dapat terjamin.

PRA adalah suatu metode pendekatan untuk mempelajari kondisi dan kehidupan pedesaan dari, dengan, dan oleh masyarakat desa. Atau dengan kata lain dapat disebut sebagai kelompok metode pendekatan yang memungkinkan masyarakat desa untuk saling berbagi, meningkatkan, dan menganalisis pengetahuan mereka tentang kondisi dan kehidupan desa, membuat rencana dan bertindak (Chambers, 1995). 


\section{REALISASI PROGRAM}

Pelaksanaan program kerja KKN 61 selama 1 bulan terhitung mulai tanggal 07 Agustus - 05 September 2018 di Kp. Cigoong RT/RW 01-02/07 Des. Puraseda Kec. Leuwiliang Kab. Bogor adalah sebagai berikut:
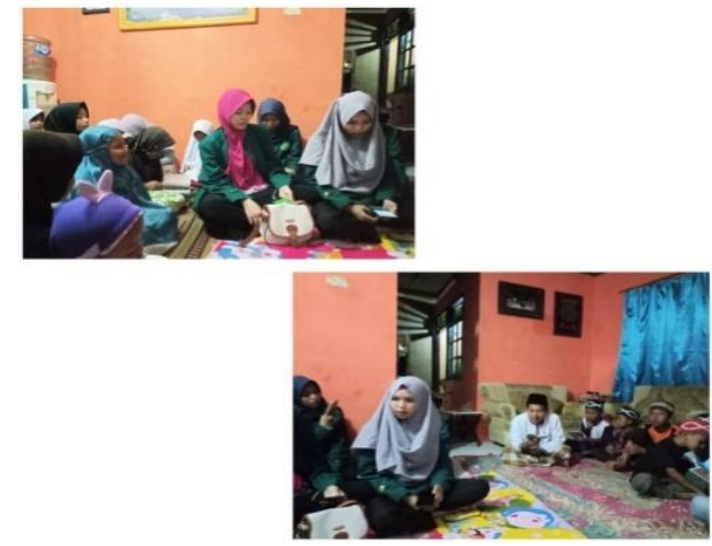

\section{TPA (Taman Pengajian Anak-anak)}

TPA (Taman Pengajian Anak-anak) merupakanwadah yang berfungsi untuk menjembatani dan memfasilitasi anak-anak dalam mempelajari iqro atau Al-Quran baik dalam Tahsin maupun Tahfiz. Programini dilaksanakan oleh bidang pendidikan setiap hari senin-jumat pukul 15.30 s/d selesai bertempatkan di Majlis Baabussalam.

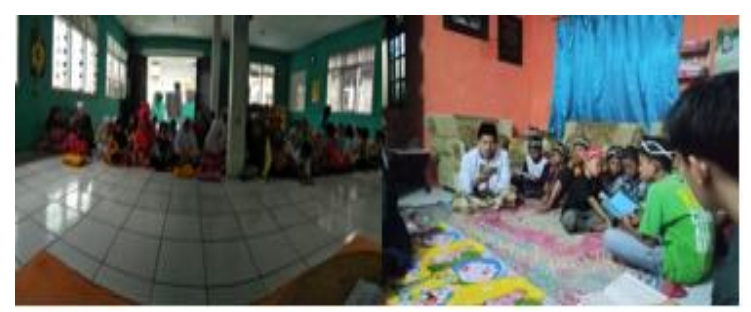

\section{Seminar Pendidikan}

Seminar pendidikan merupakan sebuah program yang dikemas dalam bentuk pemaparan materi dengan metode mendongeng, program ini bertujuan untuk memberikan pemahaman kepada anakanak dan guru agar lebih memotivasi anak dalam belajar.

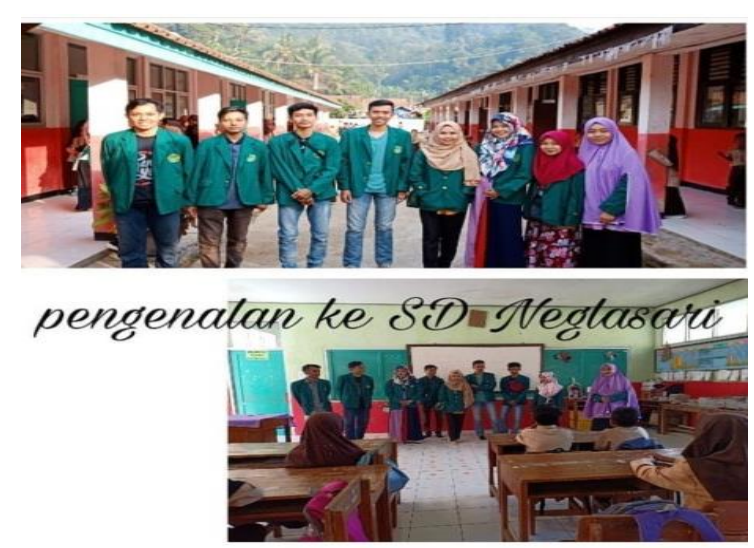

\section{Pelatihan Komputer}

Pelatihan komputer merupakan sebuah wadah yang berfungsi untuk menjembatani siswa/siswi yang mengalami kesulitan dalam mengoperasikan komputer, mengingat pendidikan masa kini telah berbasis tegnologi maka sangat diharapkan masyarakat mampu menguasai cara kerja komputer.
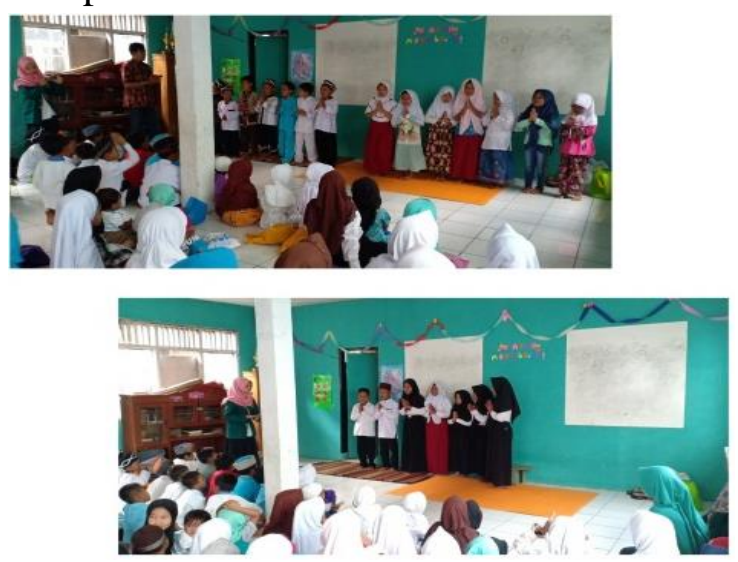

\section{Tahsin dan Tahfidz}

Tahsin merupakan kata bahasa arab yang berarti membaguskan/memperbaiki, artinya program ini dibuat untuk menjembatani siswa/siswi yang mengalami kesulitan dalam membaca Al-Qur'an ataupun membantu siswa/siswi dalam memperbaiki cara membaca Al-Qur'an yang baik dan benar. Tahfidz artinya menghafalkan atau proses mengulang/muraja'ah surat-surat pendek yang dihafal oleh anak-anak. Kegiatan ini berjalan rutin setelah shalat Ashar. 

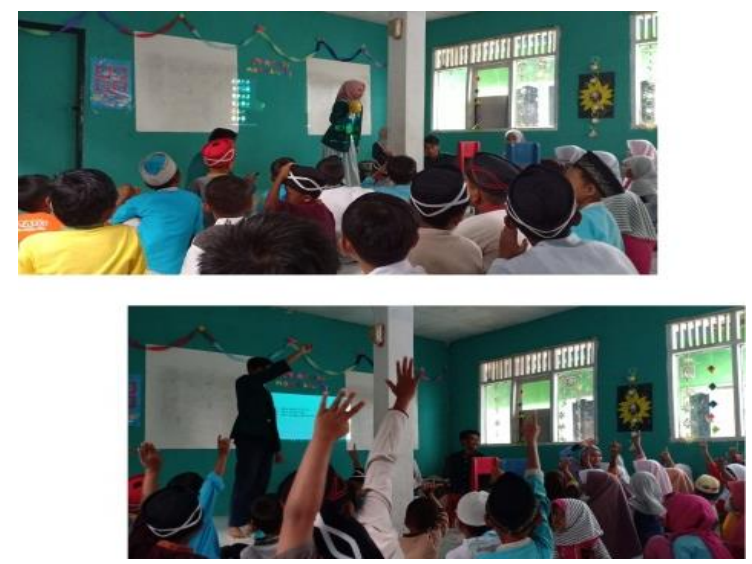

Penyuluhan Gemar Menabung

Kami melaksanakan penyuluhan gemar menabung pada hari Selasa14 Agustus 2018 pukul 16.00 - 17.00 memberikan pemaparan kepada siswa-siswi kelas 1, 2 ,3, 4, 5 dan 6 di Majlis Ta'lim Baabussalam agar bisa menabung atau menyisihkan uangnya dengan menabung, memberikan penjelasan tentang seberapa penting menanamkan budaya menabung sejak dini dan memberikan pelatihan cara membuat celengan dari bahan daur ulang seperti botol bekas. Kami pun memberikan hadiah sebuah celengan kepada semua siswa siswi bagi yang bisa menjawab pertanyaan seputar materi tentang menabung yang sudah di sampaikan oleh kami.
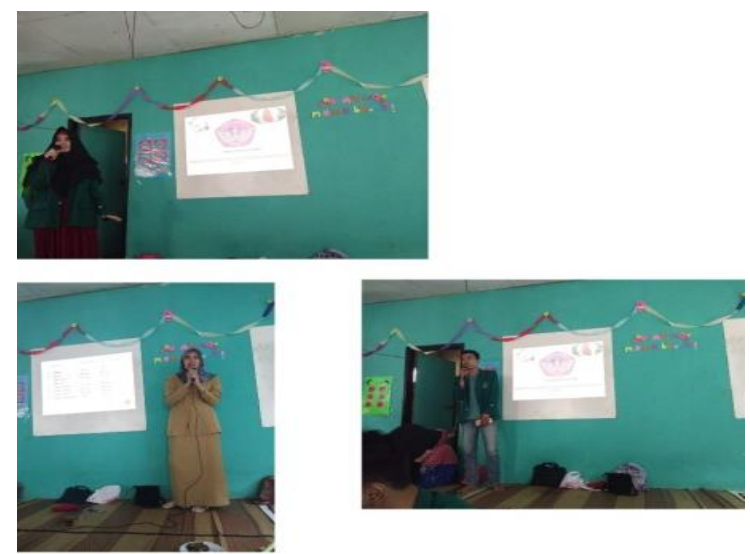

\section{Penyuluhan Hypertensi}

Kami melaksanakan penyuluhan tentang pengenalan hypertensi dan cek tensi darah pada hari Senin, 27 Agustus 2018 pukul $09.30 \mathrm{~s} / \mathrm{d} 11.30$ memberikan pengarahan kepada ibu-ibuKp. Cigoong agar meereka mengetahui pentingnya menjaga kesehatan dan tekanan darah. Dan kami pun memberikan beberapa hadiah kepada ibuibu yang bisa menjawab pertanyaan kami seputar materi tentang pengenalan hypertensi yang telah disampaikan.
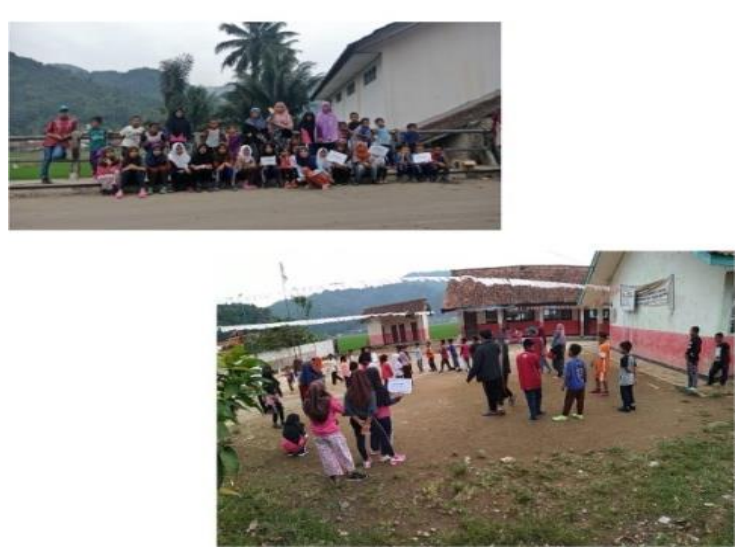

Jalan Sehat bersama warga Kp Cigoong RT 01-02 / RW 07

Pelaksanaan dilakukan pada hari Minggu26Agustus pukul 07.30 s/d 09.00.Maksud dari pelaksanaan jalan sehat ini agar anak-anak membiasakan diri agar melakukan olahraga walaupun hanya berjalan kaki. Dilakukan oleh seluruh anak-anak Kp Cigoong RT 01-02/RW 07 dari mulai anak-anak sampai dengan remaja sekalipun.
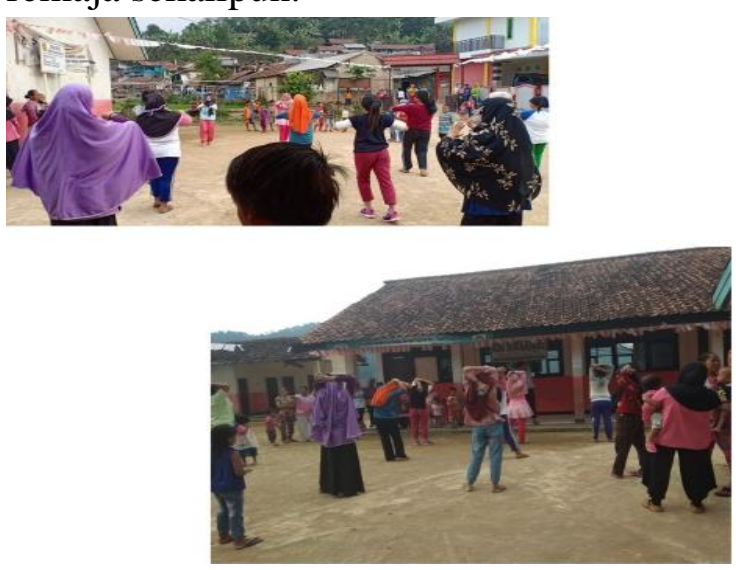

Senam Sehat Warga Kp. Cigoong RT 01-02/RW 07

Pelaksanaan di lakukan setiap hari Minggu 26 Agustus 2018 dan 02 September 2018 pukul 16.00 s/d 16.30. maksud dari pelaksanaan senam sehat ini agar ibu-ibu 
lebih bisa menjaga kesehatan tubuh dan yang terpenting adalah kebersamaan.

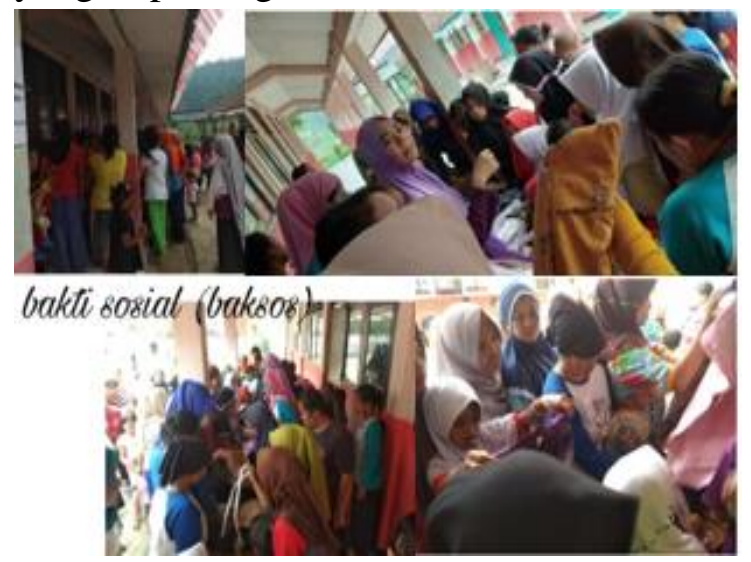

\section{Bakti Sosial (Bazar Baju)}

Pelaksanaan di lakukan pada hari Minggu 26 Agustus 2018 pukul 16.30 s/d 17.00. Maksud dari pelaksanaan bakti sosial ini adalah untuk membantu memperbaiki fasilitas masjid karena uang yang terkumpulkan hasil bazar baju tersebut disumbangkan ke masjid Kp. Cigoong. Dari masyarakat untuk masyarakat.

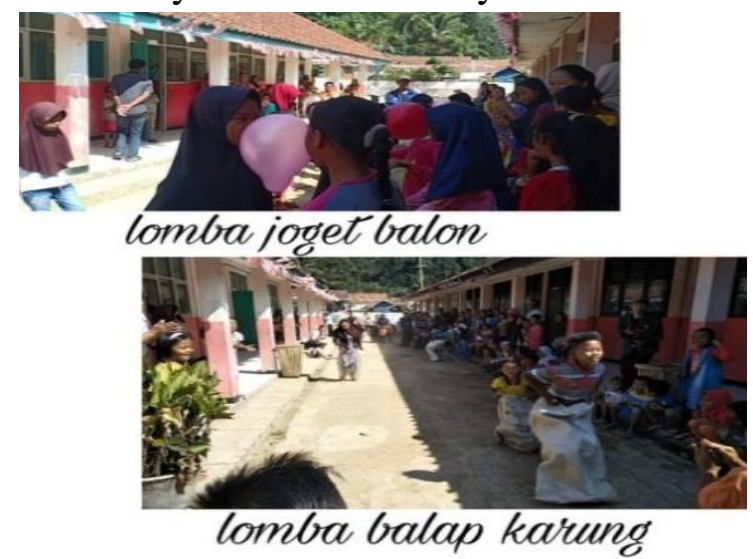

\section{Peringatan 17 Agustus}

Pelaksanaan ini dilakukan pada hari minggu 19 Agutus 2018 pada pukul 08.00 s/d. maksud dari pelaksanaan 17 agustus ini adalah untuk memeriahkan hari ulang tahun Indonesia dengan melakukan beberapa kegiatan perlombaan yang di ikuti oleh warga kampung Cigoong.
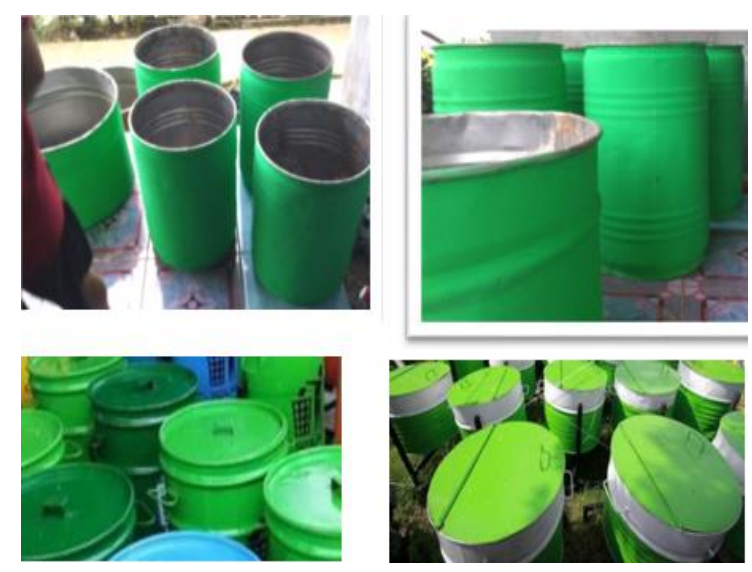

\section{Membuat Tempat Sampah}

Pelaksanaan ini dilakukan pada hari Minggu 02 September 2018 pukul 09.00 s/d 12.00. Maksud dari pelaksanaan kegiatan ini, adalah untuk membantu warga untuk membuat sampah pada tempatnya sehingga warga tidak lagi membuang sampah di sungai.

\section{KESIMPULAN}

KKN merupakan salah satu mata kuliah wajib bagi mahasiswa untuk mengabdikan diri kepada masyarakat. Hal ini ditujukan untuk melatih mahasiswa dalam hidup bermasyarakat serta untuk memberdayakan masyarakat dengan cara meningkatkan kreativitas dan kemampuan, membantu masyarakat melakukan fungsi keluarga melalui program-program .

Dalam bidang Pendidikan, Kp.Cigoong Rt 01-02 Rw 07 tergolong belum cukup baik dalam hal perhatian terhadap pentingnya pendidikan, khususnya pendidikan untuk anak usia dini. Hal tersebut terlihat dari kurangnya kesadaran orang tua yang harus memiliki semangat tinggi menyekolahkan anaknya. Pemberian bimbingan belajar atau jam tambahan belajar untuk siswa SD dan SMP merupakan salah satu hal penting yang harus diperhatikan, karena kemampuan anak dengan tingkat pendidikan yang ditempuh sesuai dengan yang diharapkan. 
Dalam bidang Kesehatan di Kp Ciogoong Rt 01-02 Rw 07 dengan adanya puskesmas puraseda dan dari segi kegiatan Posyandu, sudah tergolong baik karena intensitas kegiatan bersifat rutin dengan tim penggerak kader danPKK yang aktif.

Permasalahan Lingkungan di Kp Cigoong Rt 01-02 Rw 07. Masih kurang memadai karena tidak adanya tempat pembuangan sampah, alat pengangkut sampah dari dinas pun tidak ada. Sebagian masyarakat Kp.Cigoong Rw 07 terkadang kurang begitu peduli dengan kondisi lingkungannya, khususnyadi daerah lokasi KKN kami, sehingga kami membuat program pengadaan tempat sampah yang diletakkan diberbagai titik dan bahan percontohan untuk masyarakat Kp. Cigoong. Hal tersebut bertujuan untuk menumbuhkan kesadaran masyarakat akan pentingnya kebersihan lingkungan dengan tidak membuang sampah sembarangan.

Bidang Ekonomi di Kp Cigoong Rt 01-02 Rw 07 menunjang dengan adanya menabung sejak dini agar anak-anak terbiasa menabung atau menyisihkan uangnya dengan menabung, agar bisa menanamkan budaya menabung sejak dini dan membuat bakti sosial berupa pakaian yang masih layak pakai dengan tema "Bakti sosial membawa berkah, berbagi sambil bersedekah". Masyarakat yang mendapatkan pakaian layak pakai mereka bersedekah dengan membayar pakaian yang mereka dapatkan. Dana yang terkumpul di sumbangkan ke mesjid Kampung Cigoong.

\section{SARAN}

Dalam Bidang Pendidikan perlunya perhatian lebih dari orang tua terhadap kemajuan pendidikan anak. Adakan perpustakaan keliling agar motivasi anak untuk belajar meningkat. Adakan penyuluhan secara berkala baik itu pada peserta didik dan orang tua untuk meningkatkan motivasi pendidikan. Adakan kursuskomputer dan bahasaasing. Adakan kelompok belajar kecil bagi peserta didik.

Dalam bidang kesehatan dan lingkungan, berdayakan kembali keluarga sadar kebersihan dan kesehatan. Adakan pembinaan PKK secara berkala agar lebih professional meningkatkan kesehatan. Melakukan pengelolaan sampah secara terstruktur, adakan tempat pembuangan tempat sampah akhir dan adakan kerja bakti rutin.

Dalam bidang kewirausahaan adakan pelatihan untuk warga dalam mengolah sumber daya yang ada secara rutin. Tumbuhkan jiwa kewirausahaan pada setiap warga dan adakan penyuluhan pemanfaatan limbah rumah tangga. 
Volume 02 Nomor 04, Desember 2018

\section{REFERENSI}

Buku Pedoman KKN UIKA

Data Desa Puraseda dan Dinas Pendidikan Kecamatan Leuwiliang

Joyce, Bruce dan Weil, Marsha. (1996). Models of Teaching. Boston: Allyn and Bacon

Posyandu dan Desa Siaga Desa Puraseda http://p2sdm.ipb.ac.id/wpcontent/uploads/2014/04/STRATEGIPEMBERDAYAANMASYARAKAT.pdf

https://rivaarifin.blogspot.com/2012/03/pe ngenalan-metodepemberdayaan.html

http://addhintheas.blogspot.com/2013/04/ metode-penelitian-deskriptif.html 